\title{
Compressive Test Characteristics and Constitutive Relation of Wet Polypropylene Macrofibers Shotcrete
}

\section{Fenghui LI}

An Hui University of Science and Technology

Yunhai Cheng ( $\nabla$ chengyunhai2005@163.com )

Fei Wu

Chongqing University

\section{Chang Su}

Anhui University of Science and Technology

\section{Gangwei Li}

Anhui University of Science and Technology

\section{Research}

Keywords: dry shotcrete, wet shotcrete, wet polypropylene macrofibers shotcrete, uniaxial compression test, mechanical response, constitutive relation

Posted Date: June 22nd, 2020

DOl: https://doi.org/10.21203/rs.3.rs-36520/v1

License: (9) This work is licensed under a Creative Commons Attribution 4.0 International License. Read Full License 


\title{
Compressive test characteristics and constitutive relation of wet polypropylene
}

\section{macrofibers shotcrete}

Fenghui $\mathrm{Li}^{1,2}$, Yunhai Cheng ${ }^{3, *}$, Fei $\mathrm{Wu}^{4}$, Chang $\mathrm{Su}^{5}$, Gangwei $\mathrm{Li}^{2,6}$

1.State Key Laboratory of Mining-induced Response and Disaster Prevention and Control in Deep Coal Mines, Anhui University Of Science And Technology, Anhui Huainan 232000,China

2.School Of Mining And Safety Engineering, Anhui University Of Science And Technology, Anhui Huainan 232000,

China

3.National Engineering Laboratory of Coalmine Backfilling Mining, Shandong University of Science and Technology, Shandong Taian 271000, China

4.College of Resource and Environmental Sci. , Chongqing Univ. , Chongqing 400030, China

5.School of Mechanical Engineering, Anhui University of Science and Technology, Anhui Huainan 232000, China 6.Shandong Tianhe Technology Co., Ltd., Shandong Zoucheng 273500, China

\begin{abstract}
Shotcrete is often subject to poor ductility and cracking problems, particularly under high stresses. To address these issues, we investigated the feasibility of adding polypropylene macrofibres to shotcrete. To evaluate the supporting effect, we used dry shotcrete, wet shotcrete, and wet polypropylene macrofibre shotcrete as samples. We compared and analysed the mechanical response characteristics thereof in uniaxial compression tests by acoustic emission monitoring. The results showed that the three materials were brittle, but the ductility, residual strength, and bearing capacity of polypropylene macrofibre shotcrete were significantly enhanced. The energy absorption value of plain shotcrete was higher in the cracking stage, while that of polypropylene macrofibre shotcrete was higher in the post-peak stage, which indicated that the polypropylene macrofibre shotcrete had the characteristics of a high crack-initiation strength and toughness. Besides, the energy release from fibre shotcrete occurred after the peak stress rather than near the peak stress. The average energy absorbed by polypropylene macrofibre shotcrete was significantly higher than that in dry shotcrete and wet shotcrete, which suggested that polypropylene macrofibre shotcrete could mitigate the brittle instability of a shotcrete layer. Based on the test data, a constitutive model of damage statistics was established. The comparison between the experimental data and the fitting results could reflect the characteristics of the
\end{abstract}

*Corresponding author. Tel: 13721129479, E-mail: chengyunhai2005@163.com 
total stress-strain curve of such shotcrete. The results provide a basis for the optimisation of polypropylene macrofibre shotcrete layers.

Keywords dry shotcrete, wet shotcrete, wet polypropylene macrofibers shotcrete, uniaxial compression test, mechanical response, constitutive relation

\section{Introduction}

Shotcrete is a commonly used support and sealing method in geotechnical engineering works such as highway lanes and tunnels. Its stress-induced deformation is mainly divided into three stages: bonding, flexure, and a thin shell effect. Concrete bonding, compression resistance, and bending resistance strength are critical to the stability of the shotcrete layer(Moffat et al. 2017).

Dry shotcrete (hereinafter referred to as tidal spray, the conventional rotor-type sprayer cannot perform wet spray placement) has low strength, poor toughness, poor deformation resistance, etc. In addition, it cannot adapt to harsh formation conditions such as fractured substrates and high crustal stresses. Wet shotcrete can overcome the shortcomings of dry shotcrete, but there remain problems such as poor toughness and poor crack resistance(Zhou et al. 2019; Ning et al. 2019; Xu et al. 2018).

An effective way to improve the mechanical properties of concrete is to add steel fibres as an additional basic material, however, it is easy to corrode these in polypropylene macrofibre shotcrete. It is a material that is difficult to use and it cannot be dispersed uniformly. Consequently, it is difficult to use in underground geotechnical engineering works under complex, wet conditions. To address these problems, $\quad$ polypropylene macrofibres (polypropylene fibre) can be used as a substitute. The incorporation of polypropylene fibres into the concrete matrix can significantly improve the flexural strength, impact toughness, fatigue properties, post-peak ductility, and durability of concrete(Aslani et al. 2013; Caggiano et al. 2016; Chi et al. 2014; Cifuentes et al. 2013).

A new type of composite materials is formed by adding a proper amount of three-dimensionally randomly distributed polypropylene macrofibres to the wet-sprayed concrete, which improves the material properties of the concrete. Compared with the plain concrete, the wet polypropylene macrofibre shotcrete has better mechanical properties and better deformation ability(Bi et al. 2010). Hence, it can adapt to the harsh engineering geological conditions.

As a heterogeneous artificial material, concrete has complex constitutive characteristics and damage modes. Its mechanical properties can be inferred from the shape of the stress-strain curve and the way in which micro-cracks initiate, propagate, and 
ultimately lead to material instability and failure under the uniaxial compressive stress. When the internal structure can no longer bear stresses and is damaged, micro-cracks will transform the strain energy into mechanical energy. It can propagate in a concrete material in the form of an elastic wave, which can be recorded by acoustic emission (AE) sensors. By analysing the AE signal, the dynamic damage state of the material during uniaxial compression can be inferred. Therefore, AE technology is widely used to evaluate the mechanical properties of concrete materials, such as quantifying the severity of any damage(Proverbio et al. 2011; Degala et al. 2009), counting cracks(Aggelis et al. 2011; Soulioti et al. 2009; Li et al. 2019), demarcating their types and sizes(Aslan et al. 2013), acquiring knowledge of the dominant fracture mechanism(Geng et al. 2017; Shiotani et al. 1999), monitoring damage locations, and so on.

There has been much research into the mechanical properties of polypropylene macrofibre concrete. For example, Wang et al. (2018) studied the wavelet energy spectrum of AE signals during full stress-strain testing of polypropylene macrofibre concrete under different strain rates. Wang and Dong inferred different damage mechanisms using the amplitude range of recorded AE signals. Trcka et al. (2014) verified that the higher content of polypropylene fibre inhibited crack opening in lightweight concrete based on $\mathrm{AE}$ characteristic parameters. Yu et al. (2001) found that, with the increase of polypropylene fibre content, the cumulative count of $\mathrm{AE}$ ringing during split tensile failure increased, and the relationship between them was quasi-linear.

AE position detection and other indoor testing methods are used to analyse the mechanical response characteristics and constitutive relation of the uniaxial compression test of wet polypropylene macrofibre concrete, providing reference for the optimisation of such support schemes.

\section{Experimental programme}

\subsection{Experimental materials}

The dry shotcrete, wet shotcrete and wet polypropylene macrofibre shotcrete slabs required for the test were taken from a project site. The raw materials were: cement (grade 42.5); medium coarse sand with a fineness modulus greater than 2.5 , with the particle size of the stone being 5-12 mm; the dry spray quick-setting accelerator was an ordinary powdered aluminate quick-setting accelerator, and the wet-spray accelerator was an alkali-free liquid accelerator. Water-reducing admixture was added for the wet-spray method, to $0.8 \%$ of the mass of cement, which was conducive to improving the strength of the shotcrete; the water-cement ratio was 0.5 , and polypropylene macrofibres $\left(1 \mathrm{~kg} / \mathrm{m}^{3}\right)$ were added to the wet-spray concrete to make wet polypropylene macrofibre shotcrete(Niu et al. 2017), as shown in Fig. 1 and Tabl. 1. 


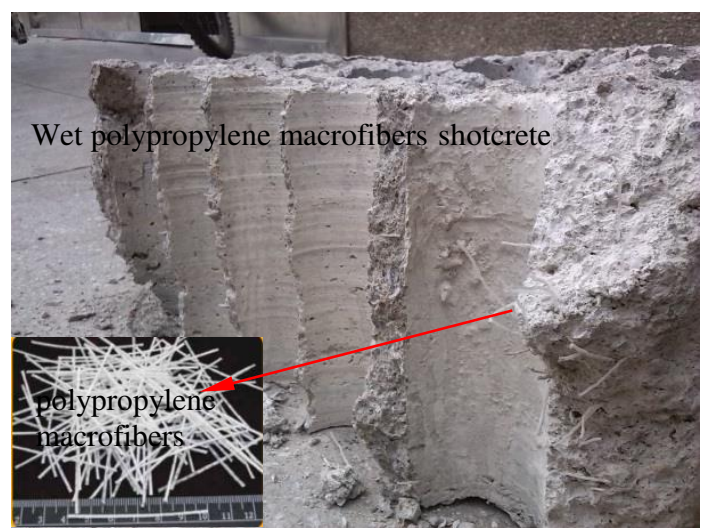

Fig. 1 Appearance of polypropylene macrofibers and drilling wet shotcrete specimen

Table. 1 polypropylene macrofibers characteristic table

\begin{tabular}{lc}
\hline \multicolumn{1}{c}{ Property of materials } & Performance description \\
\hline $\begin{array}{l}\text { Length } \\
\text { Shape structure }\end{array}$ & $48 \mathrm{~mm}$ \\
$\begin{array}{l}\text { Equivalent toughness of 50kg } \\
\text { of steel fiber }\end{array}$ & $5-8 \mathrm{~kg}$ \\
The number of fibers per & \\
kilogram & $44000-78000$ \\
Tensile strength & $530 \mathrm{MPa}$ \\
Modulus of elasticity & $7 \mathrm{GPa}$ \\
\hline
\end{tabular}
Table. 2 Ratio of shotcrete (mass ratio)

\begin{tabular}{ccccccc}
\hline Material & Cement & Sand & Stone & $\mathrm{S}_{1}$ & $\mathrm{~S}_{2}$ & fiber \\
\hline Dry shotcrete & 1 & 2 & 2 & 0.035 & & \\
Wet shotcrete & 1 & 2 & 1.75 & & 0.06 & \\
$\begin{array}{c}\text { Wet PP } \\
\text { shotcrete }\end{array}$ & 1 & 2 & 1.75 & & 0.06 & 1
\end{tabular}

Remark: $\mathrm{S}_{1^{-}}$Powdered aluminate accelerator; $\mathrm{S}_{2^{-}}$Alkalifree liquid accelerator; Water-reducing admixture $0.8 \%$

(Cement weight)

2.2 Preparation of specimens

According to Technical Code for Engineering

of Ground Anchorages and Shotcrete Support

(GB50086-2001) and the Technical Specification for

Geotechnical Anchoring and Shotcrete Support

Engineering (GB50086-2011), on-site spraying was undertaken and maintenance dimensions were 500 $\mathrm{mm} \times 500 \mathrm{~mm} \times 100 \mathrm{~mm}$ (length $\times$ width $\times$ height $)$ concrete slabs. The core method was used to make standard specimens measuring $50 \mathrm{~mm} \times 100 \mathrm{~mm}, 10$ specimens of each kind of concrete were acquired, and six standard specimens were chosen therefrom for testing (dry shotcrete test specimens Nos: G1-G6, wet shotcrete test specimens Nos: S1-S6, wet polypropylene macrofibre shotcrete test specimens Nos: X1-X6).

\subsection{Loading device and test method}

A load control system and an AE monitoring system were used in the test. The mechanical loading was applied using an RMT rock mechanics testing machine, which could record parameters such as load and vertical deformation and output the original data. The AE monitoring system could automatically collect and store various $\mathrm{AE}$ parameters. The $\mathrm{AE}$ signal acquisition was performed by eight sensors fixed on the surface of the test specimen (Figure 2) (Niu et al. 2017). The main rupture zone of the test specimens was located between the eight sensors, which could achieve real-time monitoring and threedimensional positioning of the AE signals.

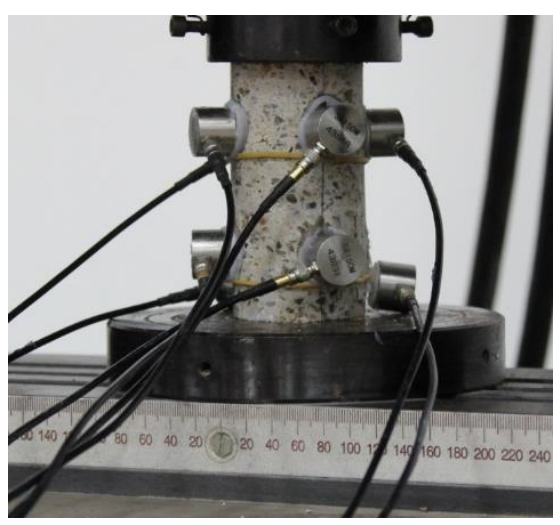

Fig. 2 Loading device and acoustic emission sensor arrangement 
To ensure the AE test effect, the AE sensor was adhered to the surface of the test specimen and fixed with a rubber band (Vaseline $^{\mathrm{TM}}$ was used as the couplant). Before the test, a pencil core was used as an analog source in a simulation test, which could check the response of the $\mathrm{AE}$ detection system to an external signal source and eliminate the external interference (noise). The test was started after the debugging. During the test, the uniaxial loading test and the $\mathrm{AE}$ test were conducted simultaneously, and the loading system was used to apply axial displacement control at a rate of $2 \times 10^{-6} \mathrm{~m} / \mathrm{s}$. The loading system automatically recorded the mechanical test process parameters, and the $\mathrm{AE}$ instrument software collected the AE raw data by processing the signals received by the eight sensors.

\section{Test results and characteristics}

\subsection{Compressive stress-strain relationship and characteristics of specimens}

The stress-strain relationship of three kinds of concrete under uniaxial compression is shown in Figure 3: before the peak stress is reached, the rate of change of the stress in dry and wet shotcrete is higher than that in the wet polypropylene macrofibre shotcrete under unit strain. When the peak stress is reached, the peak strains of dry shotcrete, wet shotcrete, and wet polypropylene macrofibre shotcrete are $0.245 \%, 0.270 \%$, and $0.676 \%$. The peak strain in the wet polypropylene macrofibre shotcrete is 1.76 times and 1.50 times than that in the dry shotcrete and wet shotcrete, respectively. This means that, when the test specimen is broken, the wet polypropylene macrofibre shotcrete concrete is less deformed and that the plasticity of the wet polypropylene macrofibre shotcrete exceeds that of the dry and wet shotcrete mixes. It is still a brittle material, despite the addition of the polypropylene macrofibres, but its ductility is significantly enhanced (Liu 2011).

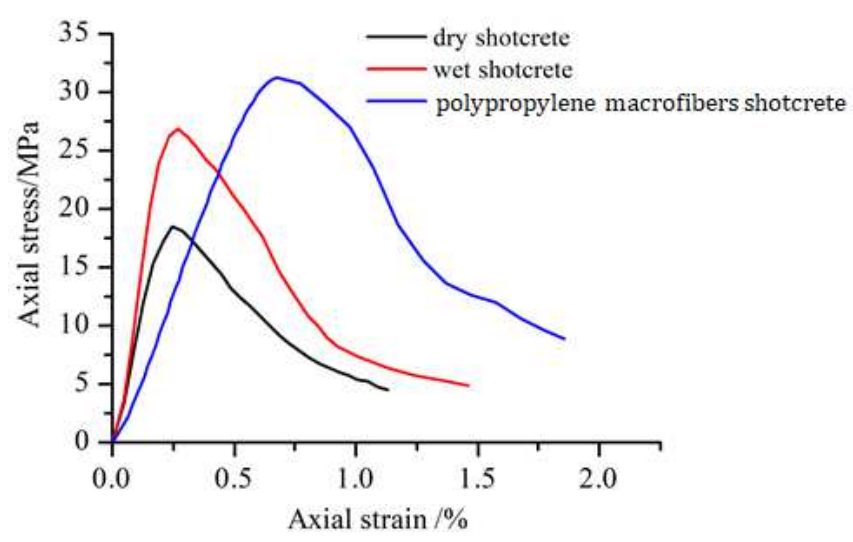

Fig. 3 Stress-strain relationships for three kinds of shotcrete under uniaxial compression

The peak stresses of dry shotcrete, wet shotcrete and wet polypropylene macrofibre shotcrete are 18.52 $\mathrm{MPa}, 26.82 \mathrm{MPa}$, and $31.21 \mathrm{MPa}$. The uniaxial compressive strength of wet shotcrete is $30.95 \%$ higher than that of dry shotcrete. There is no significant change in strain at time of failure. The uniaxial compressive strength and the strain at the onset of damage to the wet polypropylene macrofibre shotcrete increases significantly compared with those of wet shotcrete. Moreover, the 
compressive strength increases by $14.1 \%$, and the peak strain increases by $125 \%$. This shows that the wet shotcrete only improves the strength while the ability to adapt to the roadway deformation of the wet polypropylene macrofibre shotcrete is greatly improved.

Table. 3 Initial strength attenuation coefficient of three different shotcrete mixes

\begin{tabular}{cccc}
\hline $\begin{array}{c}\text { Specimen } \\
\text { code }\end{array}$ & $\begin{array}{c}\text { Dry } \\
\text { shotcrete }\end{array}$ & $\begin{array}{c}\text { Wet } \\
\text { shotcrete }\end{array}$ & $\begin{array}{c}\text { Wet polypropylene } \\
\text { macrofibers shotcrete }\end{array}$ \\
\hline 1 & 0.860 & 0.719 & 0.877 \\
2 & 0.723 & 0.665 & 0.571 \\
3 & 0.672 & 0.799 & 0.696 \\
4 & 0.805 & 0.757 & 0.650 \\
5 & 0.850 & 0.836 & 0.551 \\
6 & 0.909 & 0.682 & 0.658 \\
Average & 0.803 & 0.743 & 0.667 \\
\hline
\end{tabular}

The initial strength attenuation coefficients

(Peng et al. 2015; Zuo et al. 2017) of dry shotcrete, wet shotcrete, and wet polypropylene macrofibre shotcrete are $0.803,0.743$, and 0.667 . The initial strength attenuation coefficient of wet polypropylene macrofibre shotcrete is small, indicating its relative ductility. The wet polypropylene macrofibre

shotcrete can still bear load after the onset of damage, and provides a certain residual support, which helps to prevent the spray layer from falling.

The stress-strain curve reflects the basic mechanical properties of the three specimens and shows the strength and ductility of the specimens and the energy absorbed in the specimens: however, the energy absorbed by the specimen cannot be obtained from the stress-strain curve alone so we also studied the energy absorption of each test specimen (Table. 4). The energy absorption is obtained by integrating to get the area under the stress-strain curve.

Table. 4 Energy absorption at time of failure for three different shotcrete mixes (MPa)

\begin{tabular}{cccc}
\hline $\begin{array}{c}\text { Specimen } \\
\text { code }\end{array}$ & $\begin{array}{c}\text { Dry } \\
\text { shotcrete }\end{array}$ & $\begin{array}{c}\text { Wet } \\
\text { shotcrete }\end{array}$ & $\begin{array}{c}\text { Wet polypropylene } \\
\text { macrofibers shotcrete }\end{array}$ \\
\hline 1 & 8.381 & 10.677 & 21.946 \\
2 & 6.617 & 7.078 & 19.153 \\
3 & 7.453 & 7.346 & 20.472 \\
4 & 7.922 & 8.081 & 23.867 \\
5 & 5.155 & 6.529 & 17.875 \\
6 & 8.920 & 7.946 & 17.336 \\
Average & 7.408 & 7.943 & 20.108 \\
\hline \multicolumn{2}{c}{ The average energy absorbed by wet shotcrete }
\end{tabular}

is almost the same as that of dry shotcrete (at 0.07 times that of dry shotcrete). The average energy absorbed by wet polypropylene macrofibre shotcrete is 1.53 times that of wet shotcrete. The main reason for this is that the mechanical properties of the new material formed by adding polypropylene macrofibres to the wet shotcrete are different from those of the wet shotcrete, whose compressive strength and strain at the stress peak increase.

For the dry shotcrete, compared with the wet shotcrete, the energy absorbed by the former is always less than that absorbed by the latter (Figure 4). Therefore, the energy absorption of the concrete after the spraying process increases from the dry spraying process to the wet spraying process: the energy absorbed by the wet shotcrete in the cracking stage is high and that in wet polypropylene macrofibre shotcrete in the post-peak stage is also high. Moreover, the effect of the polypropylene macrofibres increases with increasing strain in the material. 


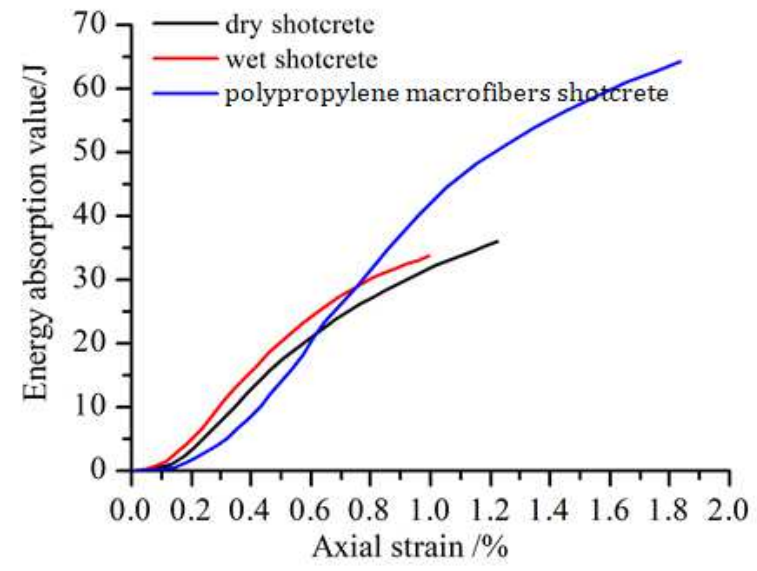

Fig. 4 Energy absorption $v$. axial strain in three different shotcrete mixes

\subsection{AE monitoring and characterisation}

The number of impacts and energy are two important $\mathrm{AE}$ parameters that reflect the activity and intensity of the AE signal. AE energy is a parameter that characterises the strength of the signal source; the number of impacts is the number of $\mathrm{AE}$ signals detected on one channel of the AE and it is used to evaluate AE activity. The AE fracture distribution can accurately reflect the space-time evolution process of the rupture position of the test specimen(Du et al. 2018; Liu et al. 2019). According to the stage change of AE energy and the number of impacts, the $\mathrm{AE}$ fracture distribution image of the typical test specimen at the moment of such a change is selected: it is then combined with AE energy and the number of impacts to study the fracture and destruction of specimens.

(1) Dry shotcrete
According to the changing stages of AE energy and the number of impacts in dry shotcrete specimens, typical samples of dry shotcrete are divided into three stages: 0-60 s (Stage I), 60-200 s (Stage II), 200 s-end (Stage III). The energy, the number of AE impacts, stresses, crack distribution, and time are coupled to obtain the four-parametertime relationship (Fig. 5).

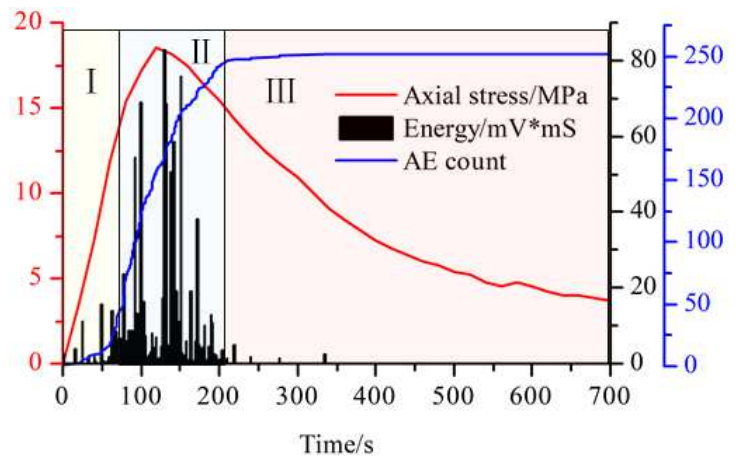

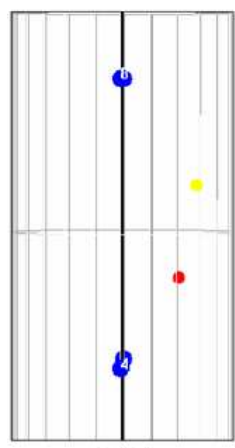

( I )

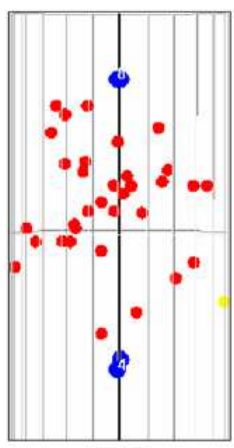

( II )

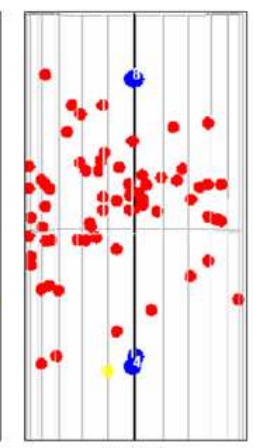

(III)
Fig. 5 Four parameter-time relationship for dry shotcrete

The dry shotcrete test has energy release from the beginning to the peak stress within 200 s. The energy release is sparse in the early stage of the test, but dense near the peak stress. Several large energy releases are generated near the peak stress, up to $82.85 \mathrm{mV} \cdot \mathrm{ms}$. The number of AE impacts increases at any time within $200 \mathrm{~s}$ from the beginning to reaching the peak stress. The number of impacts in Stage I increases slowly, then rapidly in Stage II, and 
stably in Stage III. There are few ruptures in Stage I, and a large number of scattered ruptures in Stage II. At the end of Stage III, the rupture distribution is similar to that in Stage II. The rupture data are in good agreement with the AE energy and the numbers of impacts.

(2) Wet shotcrete

According to the changing stages of AE energy and impact numbers of wet shotcrete, the typical specimens of wet shotcrete are divided into three stages: 0-140 s (Stage I), 140-330 s (Stage II), and 330 s-end (Stage III). The AE energy, the number of AE impacts, stresses, fracture distribution, and time are coupled to obtain the four-parameter-time relationship diagram (Fig. 6).

The AE energy release is observed within $200 \mathrm{~s}$ from the start of the test to reaching the peak stress. From 0 to $340 \mathrm{~s}$, the energy release is uniform with a small decrease at around 100 s. After 340 s, the energy release distribution is abnormally sparse. A large energy release occurs near the peak stress, and the released energy reaches $244.15 \mathrm{mV} \cdot \mathrm{ms}$. The wet shotcrete specimens generate a small amount of cracking in Stage I, and a large number of concentrated cracks in Stage II. At the end of Stage III, the crack distribution is akin to that in Stage II, which is in good agreement with the energy and impact data. The number of impacts increases at any time within $200 \mathrm{~s}$ from the beginning to reaching the peak stress. The number of impacts increases slowly in Stage I, rapidly in Stage II, and stably in Stage III.

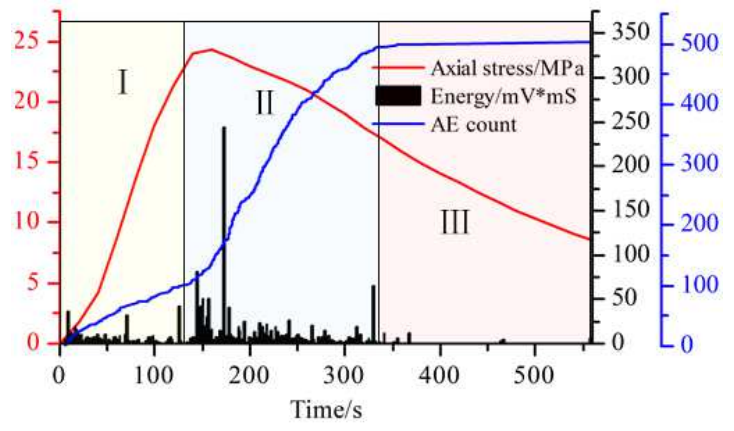

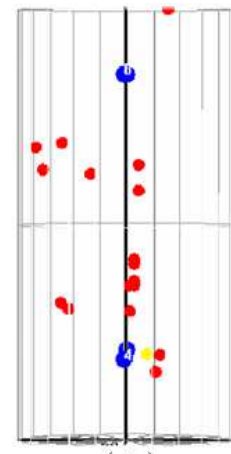

( I )

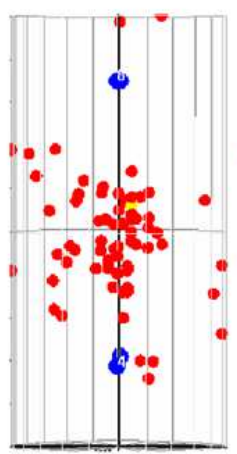

( II )

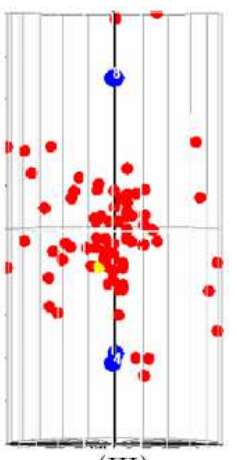

(III)
Fig. 6 Four parameter-time relationship for wet shotcrete

(3) Wet polypropylene macrofibre shotcrete

The changing stages of AE energy and the number of impacts in wet polypropylene macrofibre shotcrete are different from those of plain concrete: it shows a stable period, so the wet polypropylene macrofibre shotcrete specimens are selected between 0-10 s (Stage I), 10-410 s (Stage II), 410-560 s (Stage III), and $560 \mathrm{~s}$ to the end of trial (Stage IV). The AE energy, the number of AE impacts, stresses, fracture distribution, and time are coupled to obtain the four-parameter-time relationship diagram (Fig. 7).

The energy absorbed by wet polypropylene macrofibre shotcrete occurs mostly in Stages I and III, and only marginally Stages II and IV. There are several large energy release events in Stage III, 
reaching $177.56 \mathrm{mV} \cdot \mathrm{ms}$. Different from dry and wet shotcrete, a large amount of energy released from the wet polypropylene macrofibre shotcrete appears after, rather than at, the peak stress.

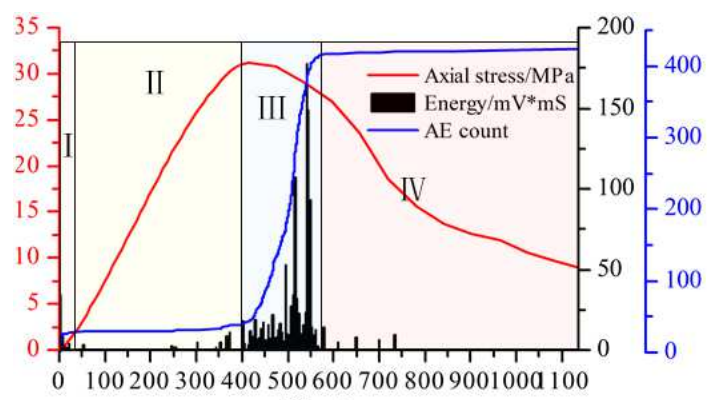
Time/s

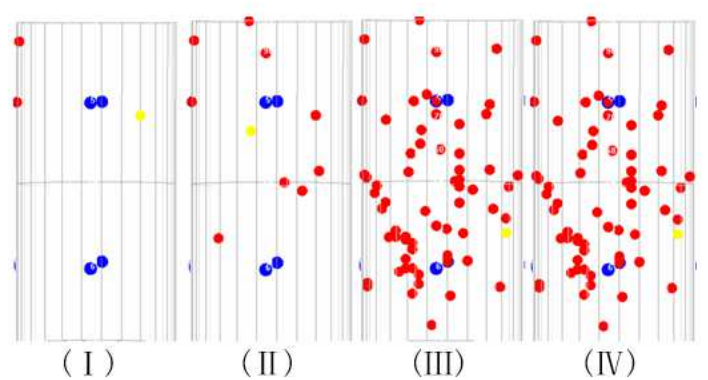

Fig. 7 Four parameter-time relationship for wet polypropylene macrofibre shotcrete

The number of AE impacts of wet imitationsteel-fibre shotcrete does not always increase: in Stage I, it rises rapidly. When the number of impacts reaches 30 , a stable period of 400 s follows which matches the concomitant stress increase. The number of impacts in Stage III increases rapidly, then decelerates in Stage IV.

A small amount of rupturing occurs at the end of Stage I. The fracture distribution is similar to that of the end of Stage I. Many uniformly distributed ruptures occur during Stages III and IV (the distribution of the fracture points therein is uniform). The fracture data are in good agreement with the AE energy and the number of impacts.

(4) AE characteristics of three shotcrete mixes

The AE signals from the three different types of concrete can be roughly divided into three stages: a smooth failure stage, severe damage stage, and later damage stage; all of which have a distinct rapid growth period, during which the concrete is destroyed and energy released rapidly.

The AE signals from the three different types of concrete exhibit the following differences:

(1) The AE signal of the wet polypropylene macrofibre shotcrete has a significant turning point before the severe failure stage while the AE signal of the ordinary shotcrete appears more uniform before the onset of severe destruction;

(2) Compared with ordinary shotcrete, the severe failure stage of wet polypropylene macrofibre shotcrete is delayed until reaching the peak stress.

(3) The distribution of the fracture points of the wet polypropylene macrofibre shotcrete is more uniform than that of ordinary shotcrete, which is conducive to improvement of the bearing capacity.

\section{Statistical damage constitutive model}

To explore the differences of different kinds of concrete constitutive relations, its damage performance is analysed. The statistical damage constitutive models of different concrete are established. The parameters of the statistical damage 
constitutive models are compared to provide reference for engineering applications.

It is known that the strength of rock and concrete materials can be described by statistical distribution and it obeys the Weibull distribution with probability density function(Angulo et al. 2020; Zhang et al. 2013; Zapata et al. 2017; Yang et al. 2004)

$$
P(\varepsilon)=\frac{m}{F}\left(\frac{\varepsilon}{F}\right)^{m-1} \exp \left[-\left(\frac{\varepsilon}{F}\right)^{m}\right]
$$

where $\varepsilon$ is the strain; $m$ and $F$ are material parameters.

If the total number of micro-elements is $N$, then the number $c$ of damaged micro-elements under a certain strain is

$c(\varepsilon)=\int_{O}^{\varepsilon} N P(x) d x=N\left\{1-\exp \left[-\left(\frac{\varepsilon}{F}\right)^{m}\right]\right\}$

Damage variable $D$ is the ratio of the number of broken micro-elements $c$, to the total number of micro-bodies $N$, so

$D=\frac{c}{N}=1-\exp \left[-\left(\frac{\varepsilon}{F}\right)^{m}\right]$

Equation (3) is the damage evolution equation of the concrete under load.

According to the theory of continuous damage mechanics, if the damaged part of concrete has no bearing capacity, its constitutive equation is

$$
\sigma=E \varepsilon(1-D)
$$

Equation (4) is applicable when concrete is under tension, but the concrete can still bear load (even under compression), hence, damage coefficient $\delta$ is introduced under the pressure condition, so the constitutive equation is

$$
\sigma=E \varepsilon(1-\delta D)
$$

Substituting Equation (3) into Equation (5):

$$
\sigma=E \varepsilon(1-\delta)+\delta E \varepsilon \exp \left[-\left(\frac{\varepsilon}{F}\right)^{m}\right]
$$

Equation (6) is the damage statistical unified constitutive model of concrete under uniaxial compression.

\section{Verification of the damage statistical constitutive model}

Based on the experimental data pertaining to the three different concrete mixes, the damage statistical constitutive model parameters are determined by using the non-linear least squares method (Table. 5). The comparison between the theoretical fitting results and the experimental data is shown in Figure 8.

Figure 8 shows that the statistical damage theoretical model is in good agreement with the experimental results and can better fit the full stressstrain curves of three types of concrete: as concrete can bear some stresses even when micro-element 
damage occurs under compression, a damage coefficient is introduced under compression to establish a damage statistical constitutive model for concrete. The model has few parameters and can reflect the characteristics of the full stress-strain curve of concrete, and thus has engineering reference value.

Table. 5 Parameters of the damage statistical constitutive model

\begin{tabular}{ccccc}
\hline \multirow{2}{*}{ Model } & \multicolumn{4}{c}{ Parameter } \\
& $E / G P a$ & $\delta$ & $F$ & $m$ \\
\hline Dry shotcrete & 11.823 & 0.9646 & 0.0037 & 1.4982 \\
$\begin{array}{c}\text { Wet shotcrete } \\
\text { wet polypropylene }\end{array}$ & 15.174 & 0.9682 & 0.0042 & 1.6079 \\
macrofibers shotcrete & 5.4348 & 0.8909 & 0.0105 & 3.6671 \\
\hline
\end{tabular}

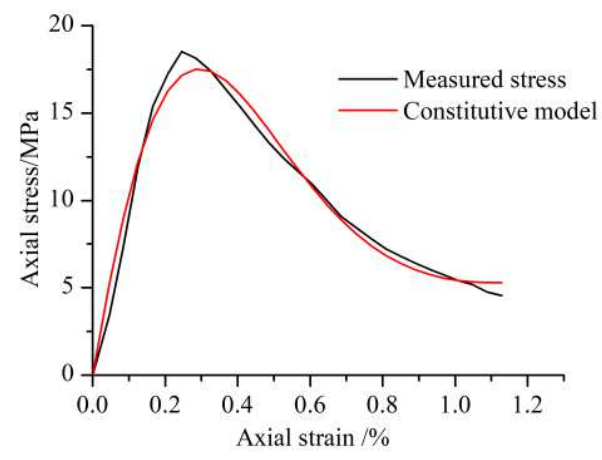

(a) Comparison of experimental data and theoretical model for dry shotcrete

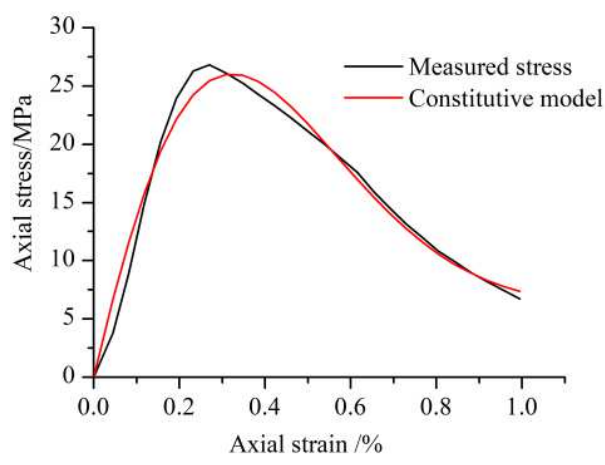

(b) Comparison of experimental data and theoretical model for wet shotcrete

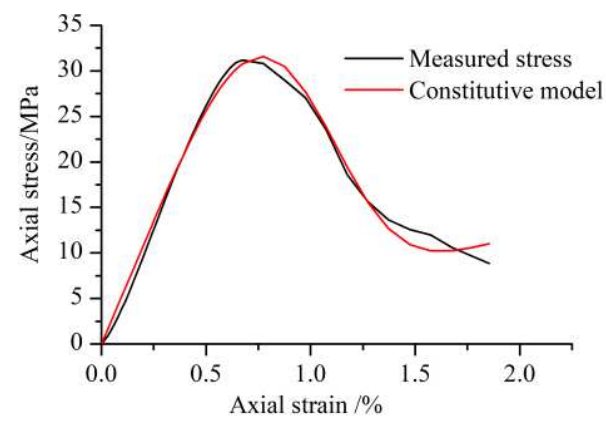

(c) Experimental data for wet polypropylene macrofibre shotcrete

Fig. 8 Comparison between experimental data and theoretical models

\section{Sensitivity analysis: the damage coefficient}

Based on the parameters determined by test data of wet shotcrete, a series of curves are obtained by changing the value of damage coefficient and keeping other parameters unchanged (Fig. 9).

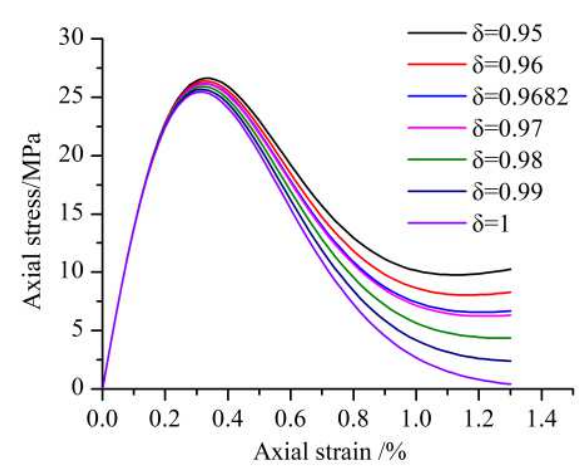

Fig. 9 Influences of damage coefficient on the total stressstrain curve

As shown in Fig. 9, the residual strength is zero when the damage coefficient is 1 ; as the damage coefficient $\delta$ decreases, the peak strength of the concrete slightly increases, but the residual strength gradually increases. That also complies with the definition of the damage coefficient. When $\delta$ is 1 , it 
implies complete damage, and the micro-element has no bearing capacity thereafter; when $\delta$ is less than 1 , it implies incomplete damage, and the micro-element can still withstand a certain stress after the onset of damage; the smaller the damage coefficient $\delta$, the greater the residual strength, which evinces material ductility.

The damage coefficients of dry shotcrete and wet shotcrete are similar (Table. 5), but the damage coefficient of wet polypropylene macrofibre shotcrete is significantly smaller than the former two. This means that the polypropylene macrofibres significantly improve the material properties of concrete(Dong 2018; Ni et al. 2017; Chen et al. 2018). The study shows that the larger the damage coefficient, the more the ductile the concrete and the greater its residual strength. Therefore, the ductility of the wet polypropylene macrofibre shotcrete has been shown to have been significantly enhanced.

\section{Conclusion}

1) The stress-strain relationship of the three concrete materials is obtained, indicating that all of them are brittle materials;

2) The mechanical properties of wet polypropylene macrofibre shotcrete are better than those of dry shotcrete and wet shotcrete. The ductility of polypropylene macrofibre shotcrete is significantly enhanced, and the residual strength is larger. It can still bear load after failure. The energy absorbed by the early-stage concrete is greater and the energy absorbed by the wet polypropylene macrofibre shotcrete is higher in the later stages of loading. The polypropylene macrofibre concrete has a high strength and good ductility at fracture initiation; the large amount of energy released from polypropylene macrofibre shotcrete occurs after reaching the peak stress while it occurs at the peak stress for the plain shotcrete. The average energy absorbed by the wet polypropylene macrofibre shotcrete is much greater than that of dry and wet shotcrete. This means that wet polypropylene macrofibre shotcrete is helpful in preventing the dynamic failure of the sprayed layer from evolving into loss of deformation stability and incipient brittle instability;

3) Based on the test data pertaining to the three different types of materials and the damage coefficients thereof, the constitutive model parameters of the damage statistics are determined by non-linear least squares method. The fitted results of the unified constitutive model are compared with the experimental data, indicating that only a few model parameters are needed to reflect the characteristics of the full stress-strain curve of concrete.

The research results provide an experimental reference for a better alternative to traditional material mix designs in the form of polypropylene macrofibre concrete support. 


\section{Data availability statements}

Some or all data, models, or code that support the findings of this study are available from the corresponding author upon reasonable request.

\section{Competing interests}

We declare that we have no financial and personal relationships with other people or organizations that can inappropriately influence our work. There is no professional or other personal interest of any nature or kind in any product, service and/or company that could be construed as influencing the position presented in, or the review of the manuscript entitled "Compressive test characteristics and constitutive relation of wet polypropylene macrofibers shotcrete".

\section{Authors' contributions}

Fenghui Li made contributions to experimental design and data analysis. Yunhai Cheng has made contributions to manuscript writing and data analysis. Fei $\mathrm{Wu}$ made a joint contribution to the statistical damage constitutive model. Chang Su and Gangwei Li completed the experiment and data collation.

\section{Acknowledgements}

Thanks to the technical staff of the relevant organizations and other members of this group for their support and assistance.

\section{References :}

Moffat R, Jadue C, Beltran JF, Herrera R (2017) Experimental evaluation of geosynthetics as reinforcement for shotcrete. Geotextiles and Geomembranes 45(3): 161-168.

Zhou G, Li SL, Ma YL, Ding JF, Zhang MG (2019) Synthesis and Properties of a Reinforcing DustCementing Material for Thin Spray-On Liners in Mine Roadways. Advances in Materials Science and Engineering Volume 2019, Article ID 8486534, 12 pages.

Ning FW, Cai YB, Bai Y, Chen B, Zhang F (2019) Effect of expansive agent and internal curing agent on crack resistance of C50 silica fume wet-mix shotcrete. Advances in Mechanical Engineering 11(1) :1-11.

Yan X, Liu LM, Zhang JP, Li YH, Wang H (2018) Experimental Study on Basic Mechanical Properties of Steel Fiber-Reinforced Siliceous Wet Shotcrete. Advances in Materials Science and Engineering Volume 2018, Article ID 1637261, 8 pages.

Aslani F, Nejadi S (2013) Self-compacting concrete incorporating steel and polypropylene fibers: Compressive and tensile strengths, moduli of elasticity and rupture, compressive stress-strain curve, and energy dissipated under compression. Composites Part B Engineering 53:121-133.

Caggiano A, Gambarelli S, Martinelli E, Nistico N, Pepe M (2016) Experiment characterization of the post-cracking response in hybrid steel/polypropylene fiber-reinforced concrete. Construction \& Building Materials 125(OCT.30):1035-1043.

Chi Y, Xu LH, Zhang YY (2014) Experimental study on hybrid fiber-reinforce concrete subjected to uniaxial 
compression. Journal of Materials in Civil Engineering 26(2):211-218.

Cifuentes H, Garcfa F, Maeso O, Medina F (2013) Influence of the properties of polypropylene fibers on the fracture behavior of low-, normal-and high-strength FRC. Construction \& Building Materials 45(aug.):130-137.

Bi YZ, Kong YF, Cai DH, Yang YW, Xia BP (2010) Application of high toughness fibers concrete in deep soft rock roadway. Journal of China Coal Society 35(12): 1969-1974(6).

Proverbio E (2011) Evaluation of deterioration in reinforced concrete structures by $\mathrm{AE}$ technique. Materials \& Corrosion 62(2) :161-169.

Degala S , Rizzo P , Ramanathan K, Harries KA (2009) Acoustic emission monitoring of CFRP reinforced concrete slabs. Construction \& Building Materials 23 (5) : 2016-2026.

Aggelis DG (2011) Classification of cracking mode in concrete by acoustic emission parameters. Mechanics Research Communications 38(3):153-157.

Soulioti D, Barkoula NM, Paipetis A, Matikas TE, Shiotani T, Aggelis DG (2009) Acoustic emission behavior of steel fibre reinforced concrete under bending. Construction \& Building Materials 23 (12) :3532-3536.

Li JJ, Huang J, Niu JG, Wan CJ (2019) Mesoscopic study on axial compressive damage of steel fibre reinforced lightweight aggregate concrete. Construction \& Building Materials 196:14-25.

Asian M (2013) Investigation of damage mechanism of flax fibre LPET commingled composites by acoustic emission. Composites Part B Engineering 54B(nov.): 289-297.

Geng JS, Sun Q, Zhang YC, Cao LW, Zhang WQ (2017) Studying the dynamic damage failure of concrete based on acoustic emission. Construction \& Building Materials $149: 9-16$

Shiotani T , Shigeishi M, Ohtsu M (1999) Acoustic emission characteristics of concrete-piles. Construction \& Building Materials 13(1):73-85.

Wang Y, Chen SJ, Zhou L, Chen YZ, Hu HX, Ge L (2018) Full Curve Damage Process of Polypropylene Fiber Reinforced Mortars under Dynamic Tensile Loading Based on Acoustic Emission Technique. Russian Journal of Nondestructive Testing 54(7):495-509.

Trcka T, Lanik J, Macku R (2014) Comparing The Properties of Polypropylene Fibers Contained in Ordinary and Lightweight Concrete Using Three-Point Bending Tests With Stress Concentrator And Acoustic Emission Method. Key Engineering Materials 537-540.

Yu R, Huang B, Zhang J, Wang J (2001) Experimental study on splitting tensile strength and acoustic emission characteristics of polypropylene fiber concrete. International Conference on Electric Technology.

Niu XA (2017) Theory and Application of Wet Imitation Steel Fiber Shotcrete Replace Reinforced Shotcrete. Dissertation, Anhui University of Science and Technology.

Liu HW (2011) Mechanics of Materials (5th Edition). Beijing: Higher Education Press, 2011:19-24.

Peng J, Rong G, Cai M, Peng K (2015) Determination of residual strength of rocks by a brittle index. rock and soil mechanics 36(2): 403-408.

Zuo JP, Chen Y, Wang C (2017) Destructive Mechanics and Models of Deep Coal-rock Combinations. Beijing: Science Press. 
Du F, Pan S, Li D (2018) Damage evaluation and failure mechanism analysis of steel tube confined reinforced-concrete columns by acoustic emission technology. Latin American Journal of Solids and Structures 15(11):e136.

Liu G, Xiao FK, Cheng QL, et al. (2019) Experimental Study on Acoustic Emission Characteristics of Dry and Saturated Basalt Columnar Joints under Uniaxial Compression and Tensile Damage. Shock and Vibration 2019(PT.1): 4971695.14971695.12.

Angulo SC, Silva NV, Lange DA, et al. (2020) Probability distributions of mechanical properties of natural aggregates using a simple method. Construction and Building Materials Volume 23310, Article 117269.

Zhang M, Wang F, Yang Q (2013) Statistical damage constitutive model for rocks based on triaxial compression tests. Chinese Journal of Geotechnical Engineering 35(11): 1965-1971.
Zapata JF, Gomez M, Colorado HA (2017) Structureproperty relation and Weibull analysis of calcium aluminate cement pastes. Materials Characterization 134:9-17.

Yang SQ, Xu WY, Wei LD, Su CD (2004) Statistical constitutive model for rock damage under uniaxial compression and its experimental study . Journal of Hehai University (Natural ences) 32(2): 200203.

Dong EY, Wang WJ, Ma NJ, Yuan C (2018) Analysis of anchor space-time effect and research of control technology considering creep of surrounding rock. Journal of China Coal Society 43(5): 1238-1248.

Ni WD, Shi AC (2017) Numerical Study on Unloading Damage of Columnar Jointed Basalt at Baihetan Hydropower Station. Journal of Yangtze River Scientific Research Institute 34(10): 85-90.

Chen L, Zhang W, Liu J, Yan LJ, Li SJ, Sun Y (2018) Research on seismic performance of slab-column shear wall structure based on collapse analysis. Building Structure 48(9): 35-42,50. 


\section{Figures}

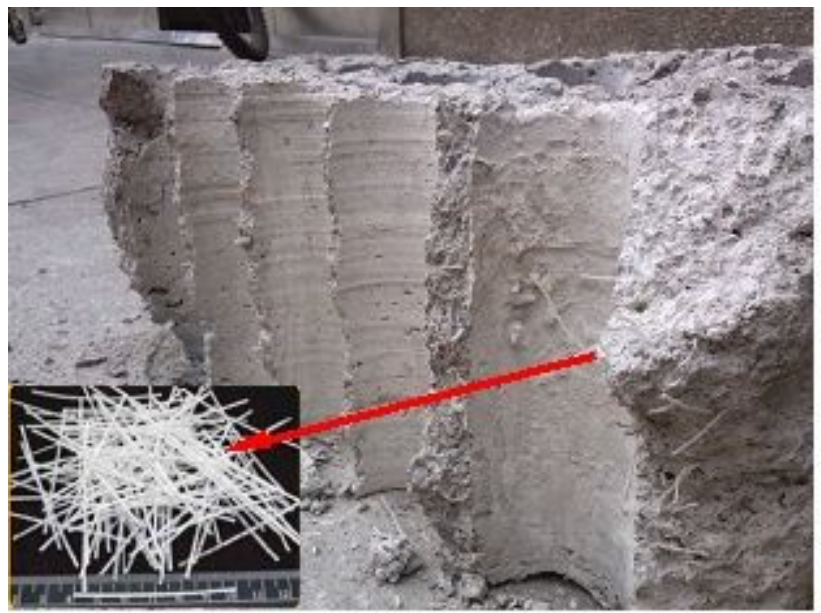

Figure 1

Appearance of polypropylene macrofibers and drilling wet shotcrete specimen

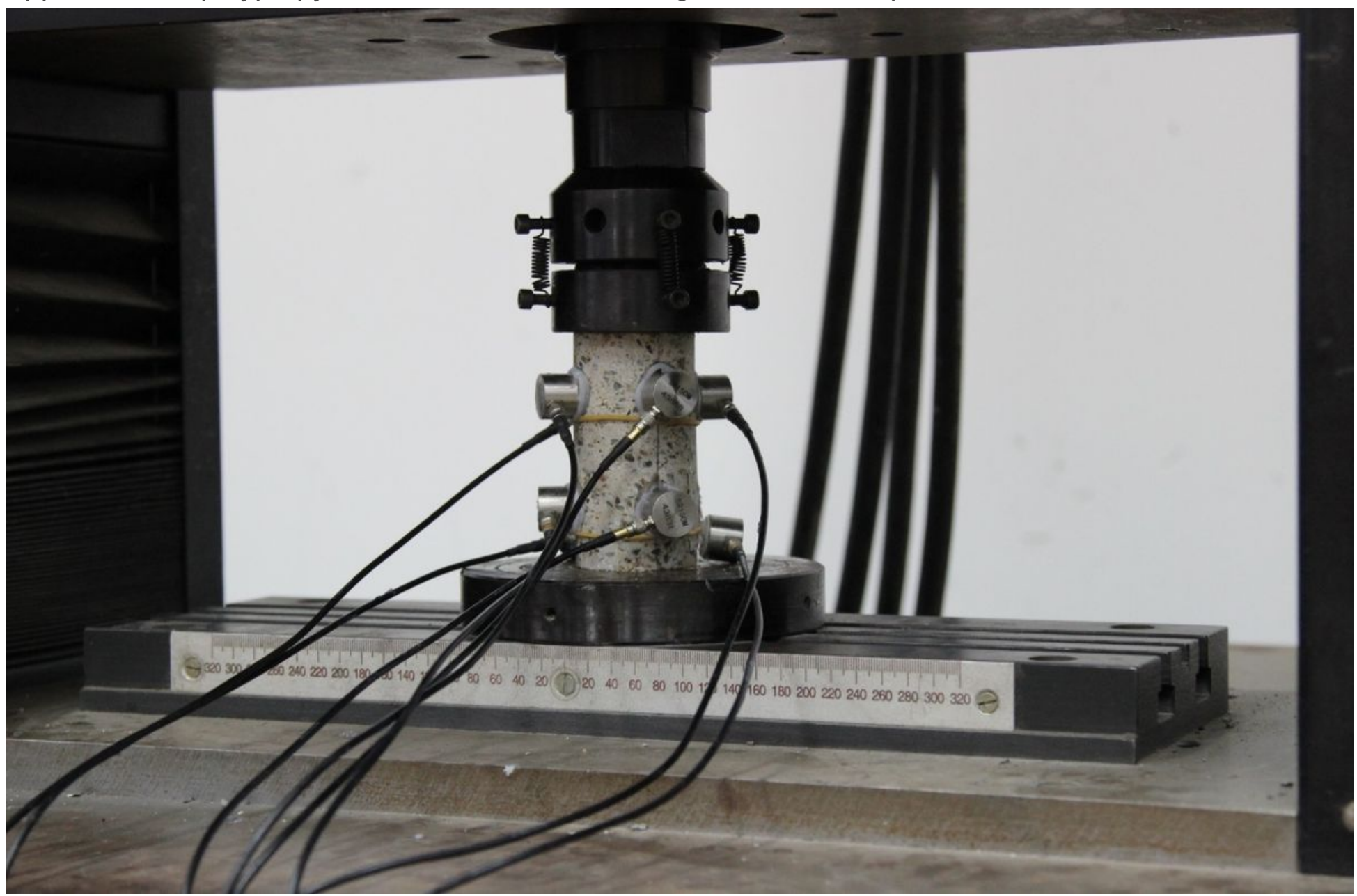

Figure 2 
Loading device and acoustic emission sensor arrangement

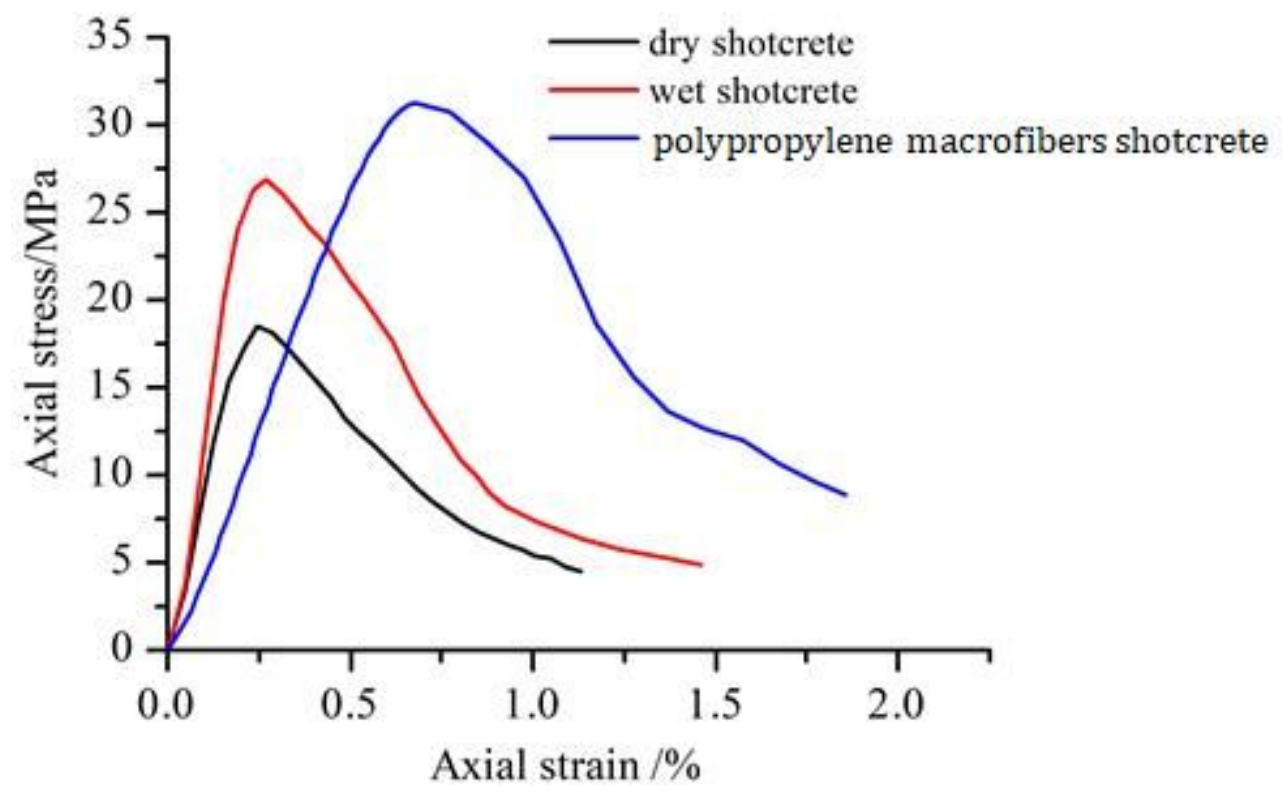

Figure 3

Stress-strain relationships for three kinds of shotcrete under uniaxial compression

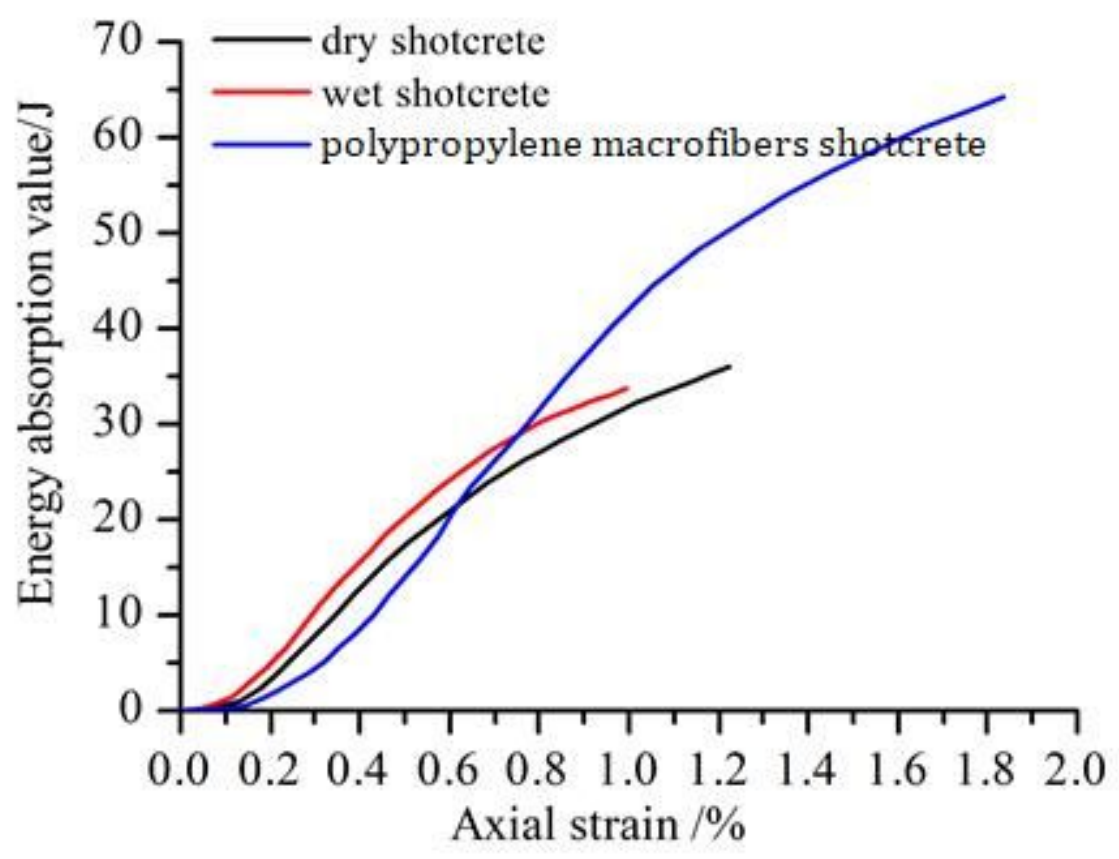

Figure 4

Energy absorption v. axial strain in three different shotcrete mixes 


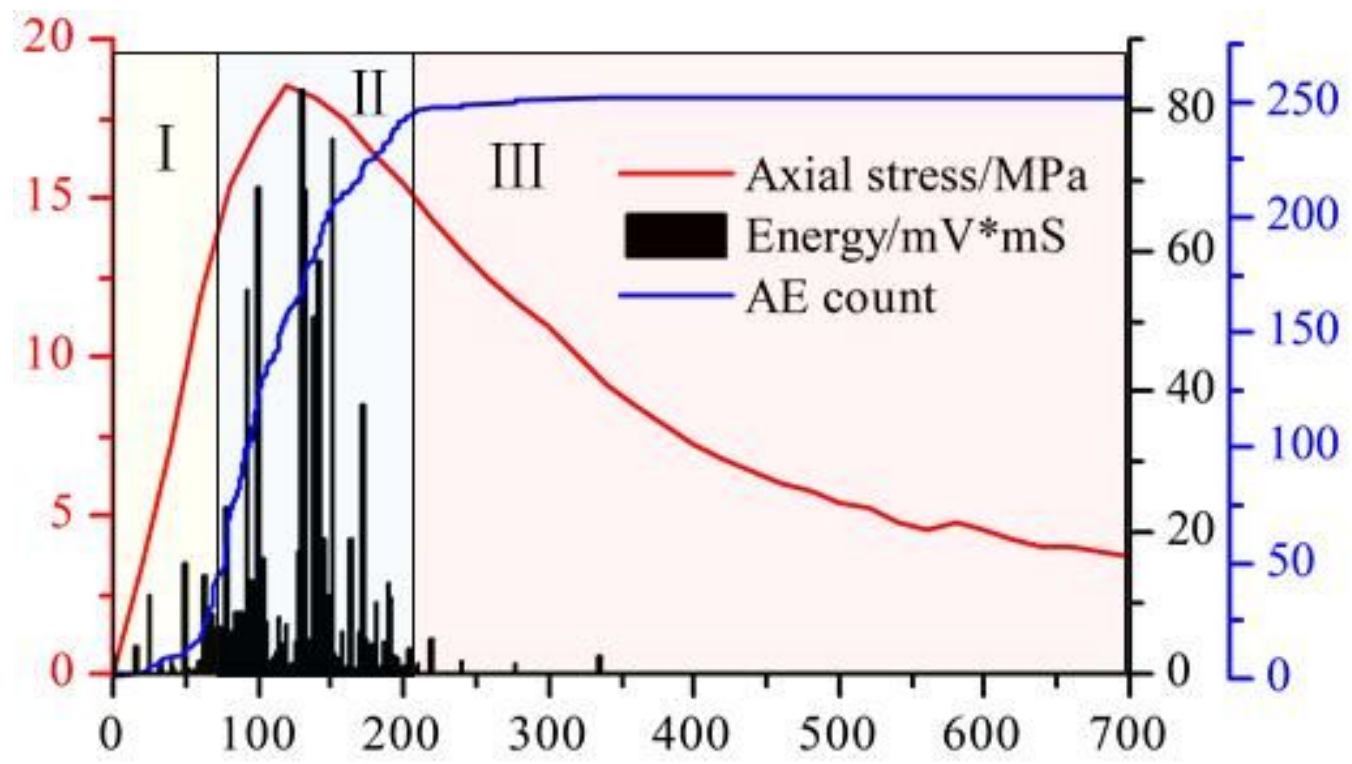

Time/s

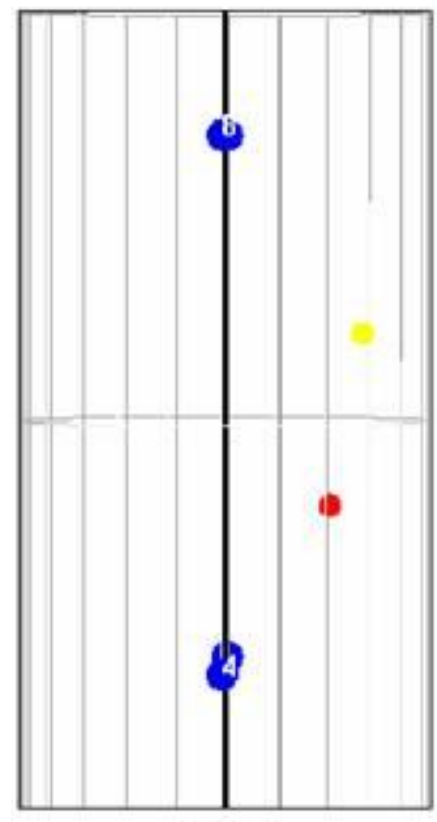

( I )

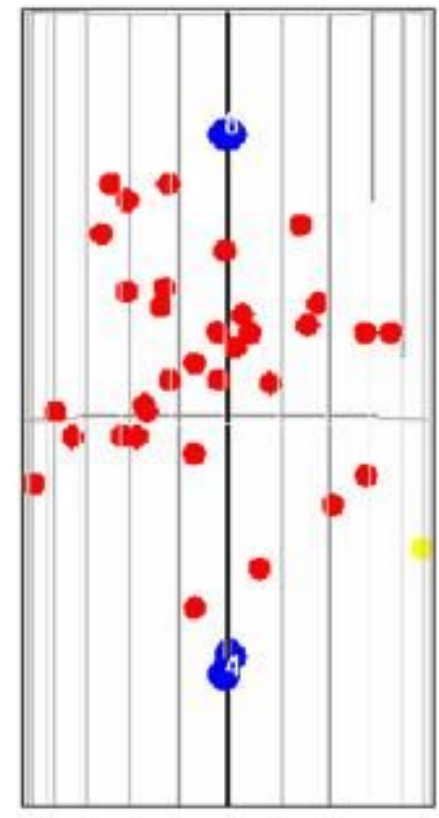

( II )

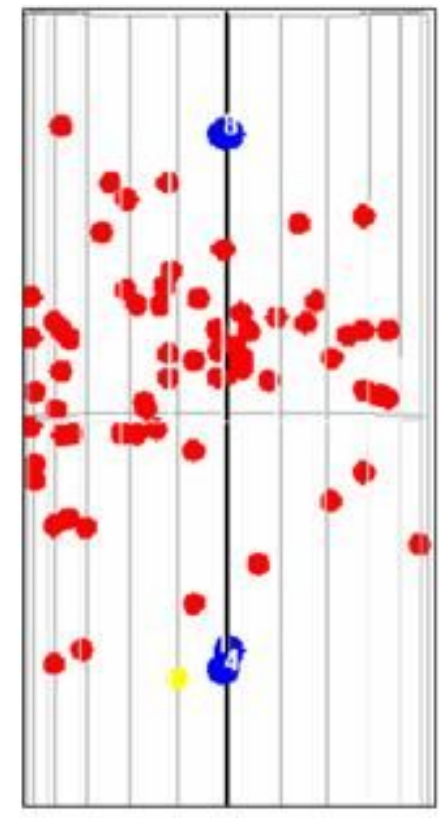

(III)

Figure 5

Four parameter-time relationship for dry shotcrete 

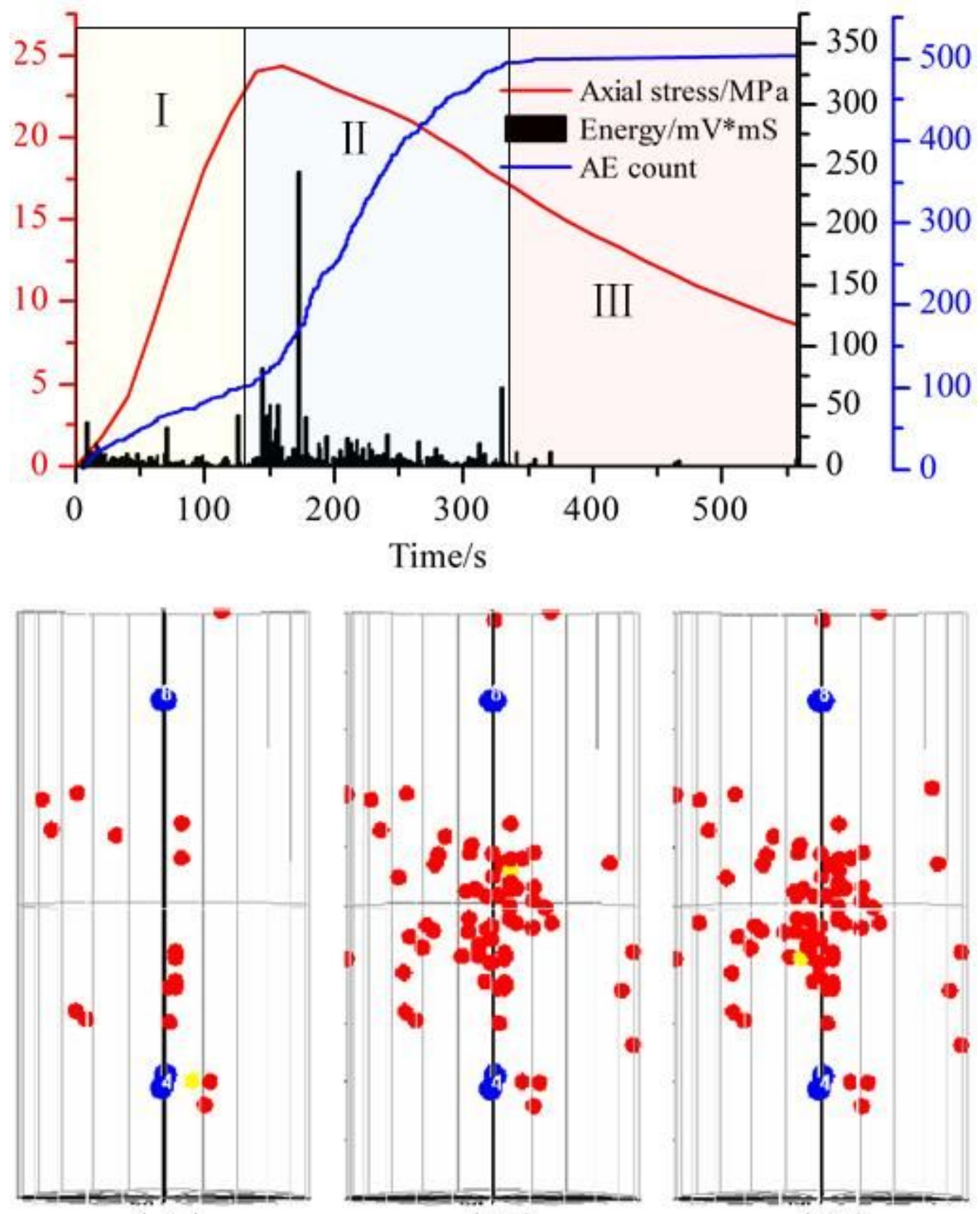

(I)

( II )

(III)

Figure 6

Four parameter-time relationship for wet shotcrete 

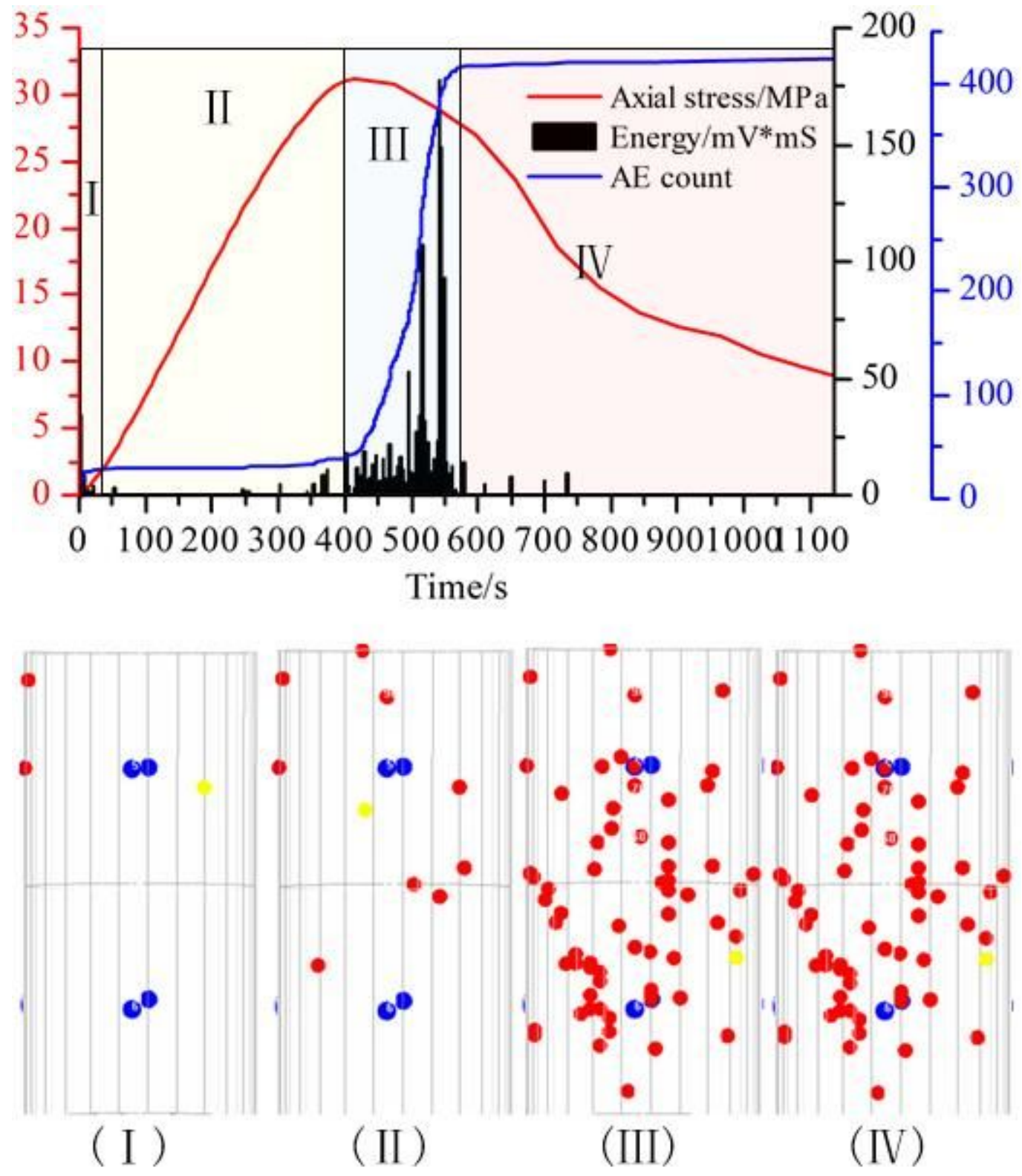

Figure 7

Four parameter-time relationship for wet polypropylene macrofibre shotcrete 


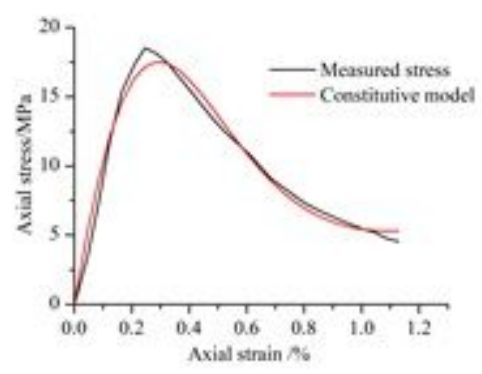

(a) Comparison of experimental data and theoretical model for dry shotcrete

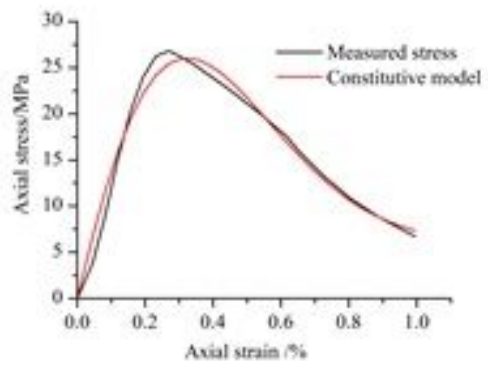

(b) Comparison of experimental data and theoretical model for wet shotcrete

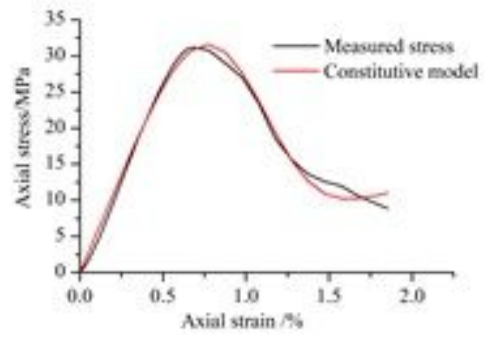

(c) Experimental data for wet polypropylene macrofibre shotcrete

\section{Figure 8}

Comparison between experimental data and theoretical models 


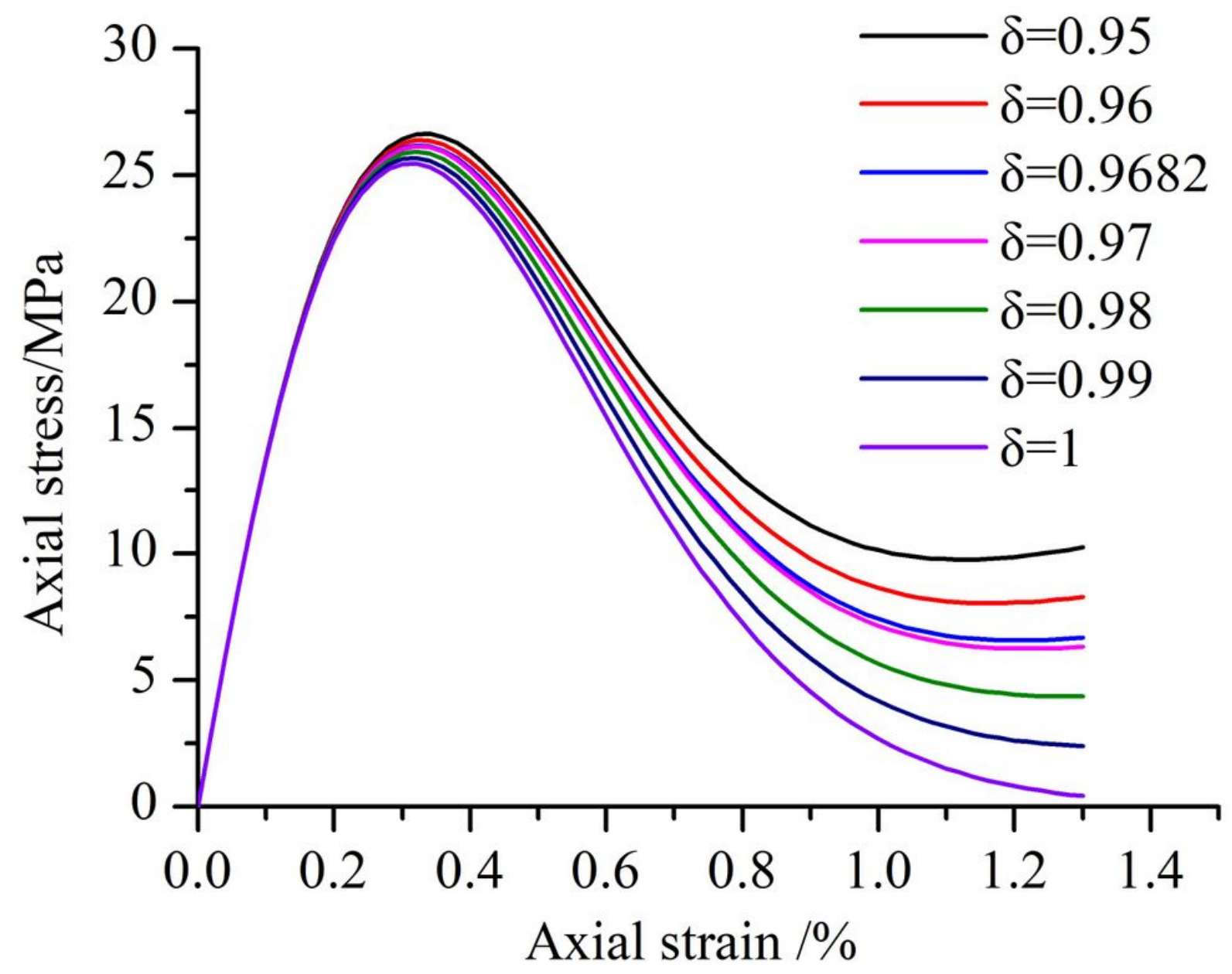

Figure 9

Influences of damage coefficient on the total stress-strain curve 